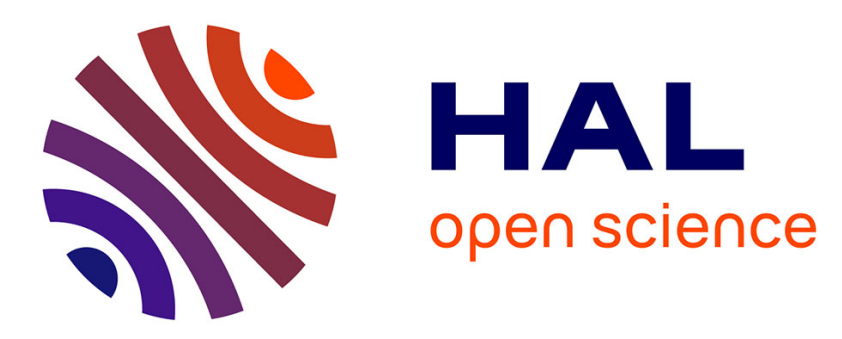

\title{
Modeling of a Coaxial Magnetic Gear Equipped with Surface Mounted PMs Using Nonlinear Adaptive Magnetic Equivalent Circuits
}

Raouf Benlamine, Tahar Hamiti, Franck Vangraefschèpe, Frédéric Dubas, Dominique Lhotellier

\section{To cite this version:}

Raouf Benlamine, Tahar Hamiti, Franck Vangraefschèpe, Frédéric Dubas, Dominique Lhotellier. Modeling of a Coaxial Magnetic Gear Equipped with Surface Mounted PMs Using Nonlinear Adaptive Magnetic Equivalent Circuits. International Conference on Electrical Machines, Sep 2016, Lauzanne, Switzerland. hal-02130956

\section{HAL Id: hal-02130956 https://hal.science/hal-02130956}

Submitted on 16 May 2019

HAL is a multi-disciplinary open access archive for the deposit and dissemination of scientific research documents, whether they are published or not. The documents may come from teaching and research institutions in France or abroad, or from public or private research centers.
L'archive ouverte pluridisciplinaire HAL, est destinée au dépôt et à la diffusion de documents scientifiques de niveau recherche, publiés ou non, émanant des établissements d'enseignement et de recherche français ou étrangers, des laboratoires publics ou privés. 


\title{
Modeling of a Coaxial Magnetic Gear Equipped with Surface Mounted PMs Using Nonlinear Adaptive Magnetic Equivalent Circuits
}

\author{
Raouf Benlamine, Tahar Hamiti, Franck Vangraefschèpe, Frédéric Dubas, and Dominique Lhotellier.
}

\begin{abstract}
This paper presents a nonlinear adaptive magnetic equivalent circuit (MEC) of a coaxial magnetic gear (MG). High speed (HS) and low speed (LS) rotors are equipped with surface mounted PMs. The stationary ring (SR) located between the rotors is constituted by magnetic iron pieces which create the flux modulation. Using the MEC, the magnetic flux density is calculated in the different parts of the MG, as well as the stall torque. In order to evaluate the reliability of the proposed model, the results are compared to 2-D finite-element analysis (FEA).
\end{abstract}

Index Terms -Flux modulation, magnetic equivalent circuit, magnetic gear, reluctances, saturation effect.

\section{INTRODUCTION}

$\mathrm{M}$ AGNETIC gears have become a very attractive choice for power transmission systems since they may offer significant advantages when compared to conventional mechanical gears. No mechanical contact is needed, which reduces the maintenance costs, the cooling, the lubrication, the breakages and the acoustic noise. Moreover, efficiency and torque density are higher, especially when coaxial topologies are used [1], [2]. In the case of coaxial (radial-flux) MGs, the permanent magnets (PMs) can be mounted on the surface of the rotors [1]-[4] or embedded in the iron, which reduces the PM eddy-current losses and improves the mechanical structure [5][7]. In addition to the coaxial MGs (or radial-flux MG), other MG topologies have been studied for different applications. Thus, when reduced axial length is required, axial-flux MGs are better suited. In [9], a surface-mounted axial-flux MG, achieving a torque density higher than $70 \mathrm{kN} / \mathrm{m}^{3}$, has been studied. The PMs can also be embedded in the iron and a higher torque density can be achieved [10]. Transverse-flux MG [11] and hybrid MG, which consists of a combination between axialflux and transverse-flux MGs [12] can be an interesting solution to improve the torque density. Nevertheless, the fabrication is more complex, which limits their application.

In order to increase the torque density of the power systems, the electrical machine can be integrated with the MG, which improves drastically the torque per volume ratio of the system, composed by the electrical machine and the MG [13]-[16] .

Due to the complex structure of MGs, numerical models using 2-D/3-D finite-element analysis (FEA) are mainly used to analyze their electromagnetic performances [1]-[16]. Analytical models can also be used to reduce the computation time [17]-[20]. However, the saturation effect is neglected, which constitutes the main limitation of the analytical models.

R. Benlamine, T. Hamiti, F. Vangraefschepe and D. Lhotellier are with the Vehicle Electrification Department, VEDECOM Institute, Versailles 78000, France (e-mail: raouf.benlamine@vedecom.fr).

F. Dubas is with the Energy Department, FEMTO-ST Institute, UMRC CNRS 6174, UBFC, Belfort 90000, France (FDubas@gmail.com).

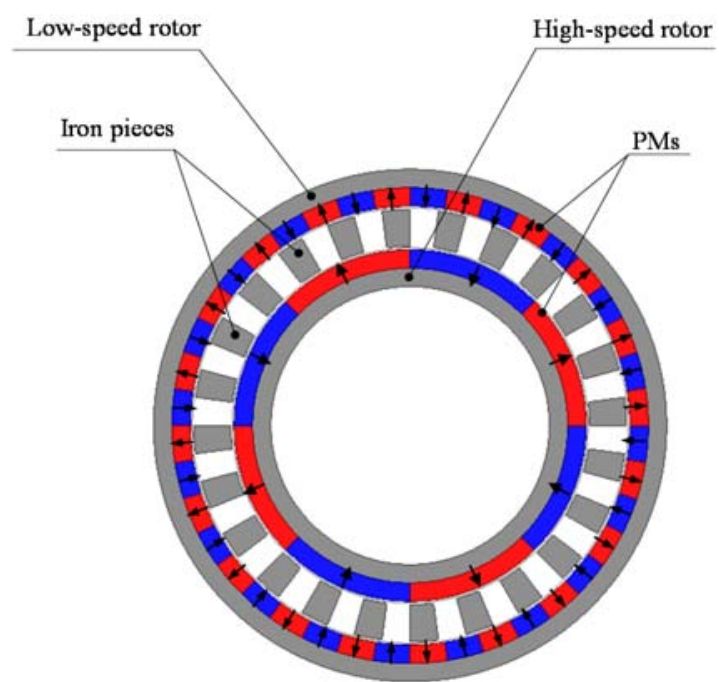

Fig. 1. Coaxial magnetic gear equipped with surface mounted PMs.

In order to account for the nonlinear $B-H$ characteristic of the iron, semi-analytical models based on the magnetic equivalent circuits can be used [21], [22]. These models have been widely developed for electric machines [23]-[29] but less for magnetic gears. It can be explained by the higher slotting effect inducing leakage fluxes, which are difficult to predict and model.

In [21], the authors have proposed a magnetic equivalent circuit of a surface-mounted MG with an automatic mesh. The discretization of the different parts of the MG (the stator, the rotors and the airgaps) is similar, and each element is composed of two tangential and two radial reluctances. The saturation effect is taken into account by considering a nonlinear equation obtained from the $B-H$ characteristic of the core material. To account for motion, the magneto-motive forces (MMF) of the PMs of each rotor are expressed by an analytical expression depending on the position of the rotors. This avoids recalculating and reorganizing the different elements of the MEC at each step time, especially the airgap reluctances, linking the different parts of the MG.

In this paper, the method developed in [27] is applied to a surface-mounted PMs MG. This method, based on nonlinear adaptive 2-D/quasi 3-D MEC, has been applied for axial and radial flux PM machines [28]-[30]. The mesh discretization is automatic and adaptive and the saturation effect is taken into account by an interpolation function. In contrary to [21], each part of the MG can be modeled separately and connected to the other parts through air-gap tangential sliding-line (SL), constituted by tangential reluctances, deducted from the relative position of the radial reluctances. These air-gap tangential reluctances insure the motion and are calculated at each step 
time. The proposed model is generic with respect to the number of pole pairs in the rotors, the number of magnetic pieces and the geometrical parameters.

In section II, the flux modulation principle, which is applied to obtain the magnetic gear, is described. Then, in section III, the studied magnetic gear and the proposed MEC are presented. Details of the mesh, the reluctance formulas and the nonlinear system solving are given. The magnetic flux density and the stall torque are calculated using the proposed model and compared to 2-D FEA. The results obtained with the proposed method are in good agreement with 2-D FEA, with an error lower than $3 \%$.

\section{DESCRIPTION OF THE FluX MODUlation PRINCIPLE}

The magnetic gear is constituted by three elements: HS rotor, LS rotor, and a stator. In some configurations, the three elements are all in motion. The operation principle is based on the flux modulation of the magnetic flux density created by a magnetic source in the internal air-gap, using iron pieces. Asynchronous space harmonics, having high amplitudes, are then generated in the external air-gap, as shown in Fig. 2. In order to choose the best pole pairs numbers combination between the two magnetic field sources, the flux density harmonics in the external air-gap has been analyzed without and with adding the intermediate iron pieces. Asynchronous harmonics appear when introducing the irons pieces, and their orders and frequencies can be given, respectively, by [2]

$$
\begin{aligned}
& p_{m, k}=\left|m \cdot p_{1}+k \cdot n_{c}\right| \\
& \Omega_{m, k}=\frac{m \cdot p_{1}}{m \cdot p_{1}+k \cdot n_{c}} \cdot \Omega_{1}+\frac{k \cdot n_{c}}{m \cdot p_{1}+k \cdot n_{c}} \cdot \Omega_{c},
\end{aligned}
$$

where $p_{1}$ is the pole pairs number of the HS rotor, $n_{c}$ is the iron pieces number, $m$ and $k$ are coefficients defined by: $m=1,3,5, \ldots$ and $k=0, \pm 1, \pm 2, \ldots \quad$ respectively, $\Omega_{1}$ represents the HS rotor speed, and $\Omega_{c}$ represents the iron ring speed. The combination $m=1$ and $k=-1$ defines the order of the highest asynchronous space harmonic amplitude (see Fig. 3). Thus, the pole pairs number of the external magnetic field source is given by

$$
p_{2}=\left|p_{1}-n_{c}\right|
$$

In the studied example, depicted in Fig. 1, the pole pairs numbers of the two magnetic sources and the iron pieces number are $p_{1}=4, p_{2}=20$ and $n_{c}=24$, respectively.

If the intermediate ring is considered as stationary (i.e., $\Omega_{c}=0$ ), the gear ratio is given by

$$
G_{r}=-\frac{n_{c}-p_{1}}{p_{1}}
$$

The negative sign indicates that the two rotors rotate in opposite directions.
Another configuration can be obtained by maintaining the external part fixed (i.e., $\Omega_{2}=0$ ), the gear ratio is equal to

$$
G_{r}=\frac{n_{c}}{p_{1}}
$$

In this case, the intermediated ring (LS rotor) rotates in the same direction as the HS rotor. Moreover, the gear ratio is higher than that of the previous configuration.

In this study, the first configuration is considered. However, the second one can be studied using the proposed method.

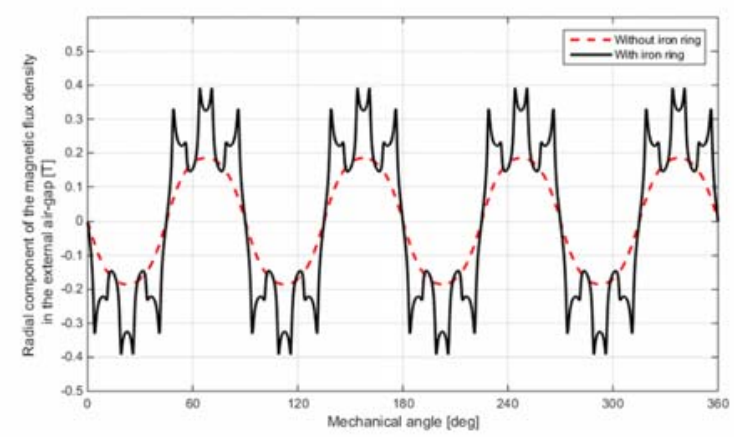

(a)

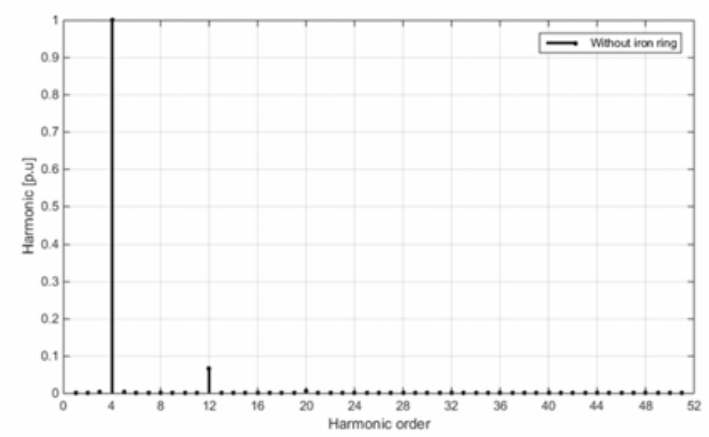

(b)

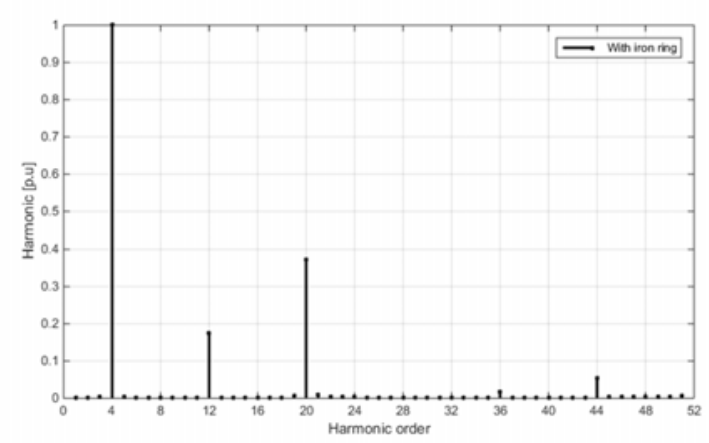

(c)

Fig. 2. Magnetic flux modulation principle : (a) magnetic flux density in the external air-gap, (b) space harmonics without iron pieces, et (c) space harmonics with iron pieces. 


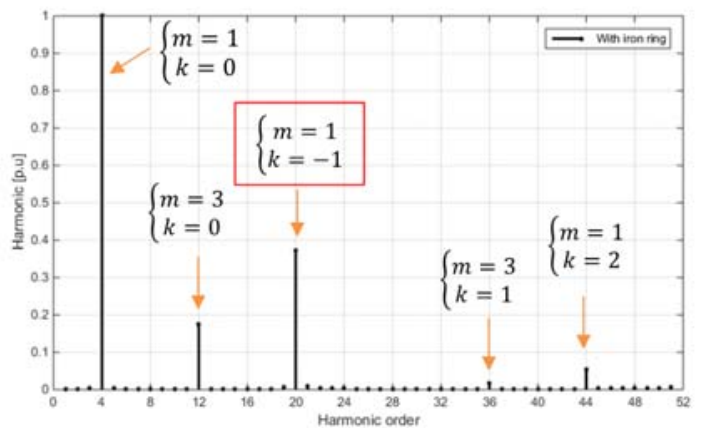

Fig. 3. Identification of the space harmonic orders using the combinations $(m, k)$.

\section{Description OF THE Proposed MEC}

\section{A. Description of the Magnetic Gear}

The studied MG is depicted in Fig. 1. As mentioned in the previous section, the intermediate iron pieces are considered as stationary, and the external LS rotor rotates in the opposite direction of the internal HS rotor. The main geometric and magnetic parameters are described in

TABLE I.

\section{B. List of Assumptions}

Different assumptions have been considered in the proposed MEC: - the PMs are radially magnetized;

- all the magnetic gear regions have radial faces;

- the end-effects are neglected;

- Dirichlet condition is applied according the inner and outer diameter of the MG.

\section{Automatic Mesh of the $M G$}

The MG is considered as composed by two rotating zones (i.e., HS and LS rotors) and a stationary zone (i.e., the intermediate ring). Each zone can be modelled independently. As shown in Fig. 4, each zone can be meshed independently and considering different discretizations. The connection between static and rotating zone is accomplished using the air-gap tangential reluctances. Only these reluctances vary with motion. An example of mesh is presented in Fig. 5.

\section{Reluctance Calculation and Nonlinear System Solving}

The analytical expressions of the radial and tangential reluctances are given by [30]

$$
\begin{aligned}
& \mathfrak{R}_{r}^{i}\left(B_{i}\right)=\frac{1}{\mu_{0} \cdot \mu_{r_{i}}\left(B_{i}\right) \cdot L} \cdot \frac{1}{\Theta^{i}} \cdot \ln \left(\frac{R_{\text {out }}^{i}}{R_{\text {in }}^{i}}\right) \\
& \mathfrak{R}_{\Theta}^{i}\left(B_{i}\right)=\frac{1}{\mu_{0} \cdot \mu_{r_{i}}\left(B_{i}\right) \cdot L} \cdot \Theta^{i} \cdot \frac{1}{\ln \left(\frac{R_{\text {out }}^{i}}{R_{\text {in }}^{i}}\right)}
\end{aligned}
$$

where $\mu_{0}$ is the vacuum permeability, $L$ is the stack length of the machine, $B_{i}, \Theta_{i}, R_{i n}^{i}, R_{\text {out }}^{i}$ are, respectively, the magnetic flux density, the opening angle, the inner radius and the outer radius of the reluctance $i, \mu_{r_{i}}\left(B_{i}\right)$ is the relative permeability of the reluctance $i$ defined by

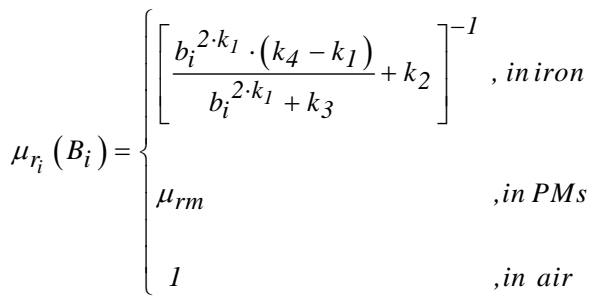

where $\mu_{r m}$ is the relative permeability of the PMs , $b_{i}$ represents the magnetic flux density $B_{i}$ divided by $1 T$, and $k_{1} \sim k_{4}$ are the interpolation coefficients obtained by minimizing the square-error between the $B-H$ characteristic provided by the manufacturer and the values obtained using the Marrocco's function [31] The steel laminations Arcelor Mittal M330-35A have been used for the studied MG. The interpolation coefficients are reported in TABLE II and the obtained curve is depicted in Fig. 6.

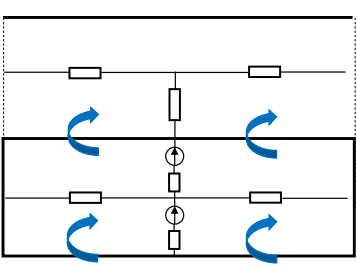

(a)

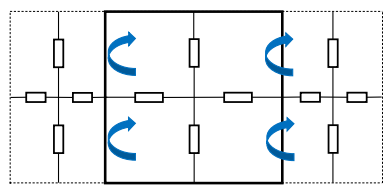

(c)

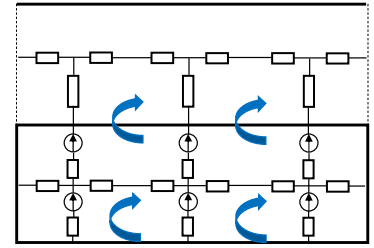

(b)

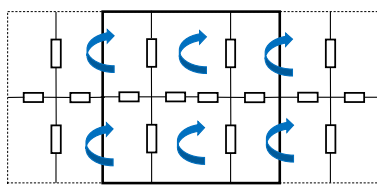

(d)
Fig. 4. Elementary and improved mesh of : (a-b) pole-pitch, and (c-d) tooth-pitch

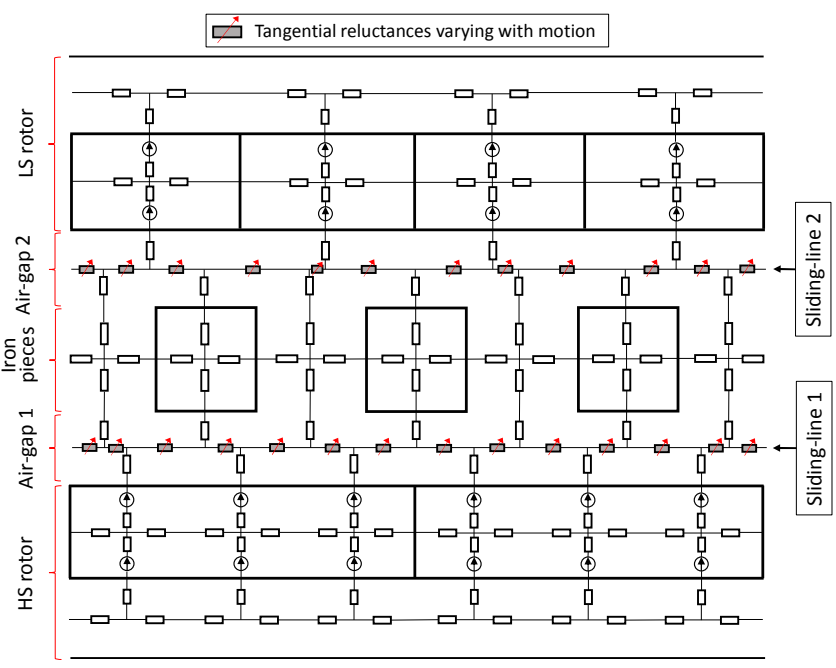

Fig. 5. Example of magnetic gear mesh 
TABLE I

GeOmetric And Magnetic Parameters.

\begin{tabular}{|c|c|}
\hline Parameters & Values \\
\hline Inner radius of the HS rotor, $[\mathrm{mm}]$ & 38 \\
\hline Outer radius of the LS rotor, $[\mathrm{mm}]$ & 70 \\
\hline Pole pairs number of the HS rotor, $p_{1}$ & 4 \\
\hline Pole pairs number of the LS rotor, $p_{2}$ & 20 \\
\hline Iron pieces of the intermediate ring, $n_{c}$ & 24 \\
\hline Yoke thickness of the HS rotor, $[\mathrm{mm}]$ & 5 \\
\hline Yoke thickness of the LS rotor, $[\mathrm{mm}]$ & 5 \\
\hline Iron pieces thickness, $[\mathrm{mm}]$ & 10 \\
\hline PMs thickness of the HS rotor, $[\mathrm{mm}]$ & 5 \\
\hline PMs thickness of the LS rotor, $[\mathrm{mm}]$ & 5 \\
\hline Angular PM span to pole-pitch ratio (HS rotor), & 1 \\
\hline Angular PM span to pole-pitch ratio (LS rotor), & 1 \\
\hline Angular iron piece angle to tooth-pitch ratio, & 0.5 \\
\hline Internal air-gap length, $[\mathrm{mm}]$ & 1 \\
\hline External air-gap length, $[\mathrm{mm}]$ & 1 \\
\hline Rotation speed of the HS rotor, $\Omega_{1}[\mathrm{rpm}]$ & 6,000 \\
\hline Rotation speed of the HS rotor, $\Omega_{2}[\mathrm{rpm}]$ & $-1,200$ \\
\hline Rotation speed of the intermediate ring, $\Omega_{c}[\mathrm{rpm}]$ & 0 \\
\hline Gear ratio, $G_{r}$ & 5 \\
\hline Iron stack length, $L[\mathrm{~mm}]$ & 100 \\
\hline Residual flux density at $T_{m 0}=20^{\circ} \mathrm{C}, B_{r m 0}[T]$ & 1.3 \\
\hline Relative magnetic permeability, $\mu_{r m}[-]$ & 1.05 \\
\hline
\end{tabular}

TABLE II

INTERPOLATION COEFFICIENTS OF MARROCCO'S FUNCTION FOR THE M330-35A STEEL.

\begin{tabular}{ccc}
\hline \hline Coefficient & Values & Units \\
\hline$k_{1}$ & 6.38 & - \\
$k_{2}$ & $1.62 \times 10^{-4}$ & - \\
$k_{3}$ & $6.27 \times 10^{4}$ & - \\
$k_{4}$ & 6.69 & - \\
\hline \hline
\end{tabular}

By using the Marrocco's interpolation function, the nonlinear effect in iron reluctances can be taken into account iteratively during the magnetic field calculation. The flowchart describing the different steps of the nonlinear system solving is presented in Fig. 7, where $[F]$ is the magnetic and electric sources vector,

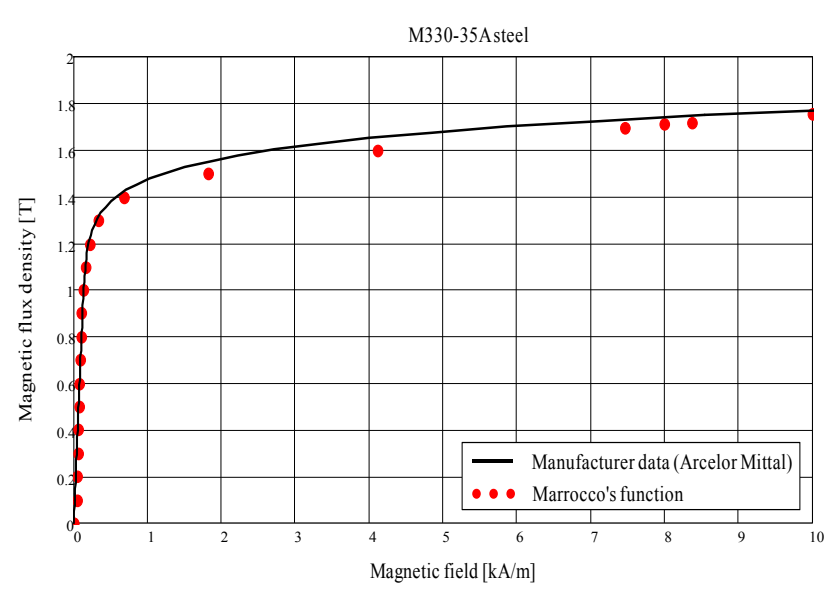

Fig. 6. Interpolation of $B-H$ characteristic for the M330-35A steel.

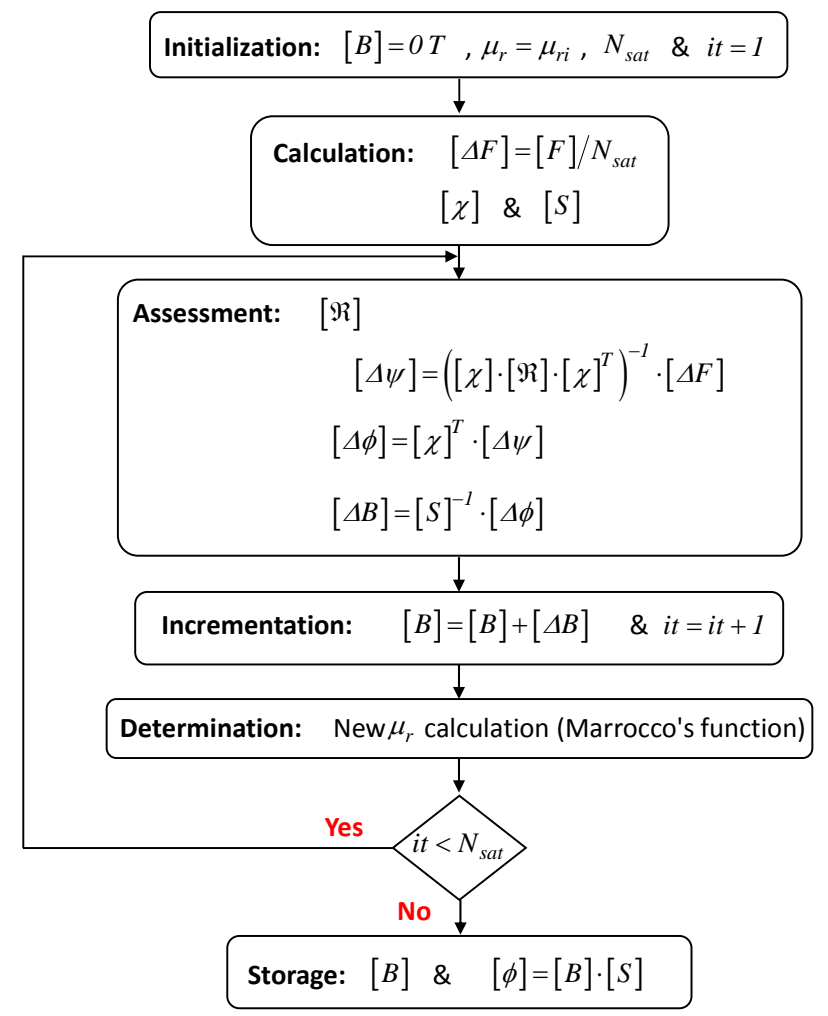

Fig. 7. Flowchart of the nonlinear system solving [27].

$[\chi]$ is the total incidence matrix, $[\psi]$ and $[\phi]$ represent, respectively, the loop and the reluctance fluxes, and $[\Re],[S]$ are the total reluctances matrix and their surfaces [27]-[30].

\section{Finite ELEMENT ANALySIS AND RESUlt COMPARISON}

\section{A. Description of 2-D FEA}

The 2-D FEA has been performed using ANSYS Maxwell ${ }^{\circledR}$ software package. Due to the boundary conditions (i.e., periodicity), periodicity can be used so that only 1 quarter of the MG is analyzed [see Fig. 8]. 


\section{B. Magnetic Flux Density Calculation}

The magnetic flux density has been calculated using the MEC and compared to the results obtained by 2-D FEA. Different paths are considered in different parts of the MG. The main paths are located in:

- HS rotor yoke;

- iron pieces;

- LS rotor yoke;

- internal and external air-gaps.

Both radial and tangential components of the magnetic flux density have been calculated and compared to 2-D FEA.

\section{Stall and Electromagnetic Torque Calculation}

The stall torque has been calculated using the Maxwell stress tensor, given by

$$
T_{e m}\left(\Theta_{r \mathrm{~s}}\right)=\frac{1}{\mu_{0}} \cdot L \cdot R_{a g}^{2} \cdot \sum_{i}\left[\left(B_{r_{a g}}\right)_{i} \cdot\left(B_{\Theta_{a g}}\right)_{i} \cdot\left(\Theta_{a g}\right)_{i}\right]
$$

where $B_{r_{a g}}$ and $B_{\Theta_{a g}}$ are the radial and tangential components of the air-gap magnetic flux density, and $\Theta_{a g}$ is the mechanical angles vector of the tangential air-gap reluctances at each mechanical rotation angle $\Theta_{r s}$ (or step time).

The external LS rotor is maintained fixed.

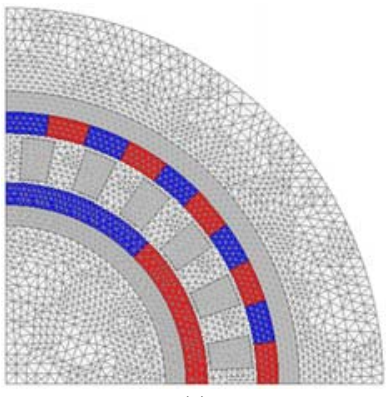

(a)

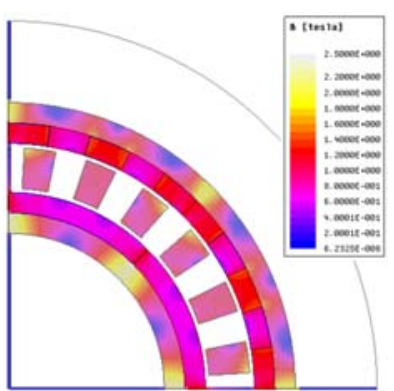

(c)

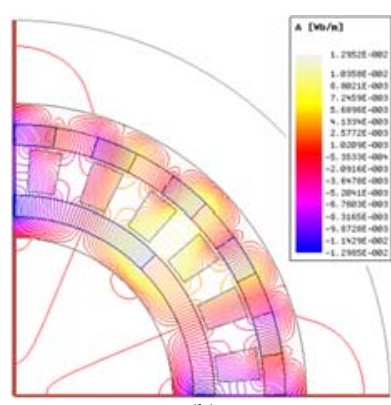

(b)

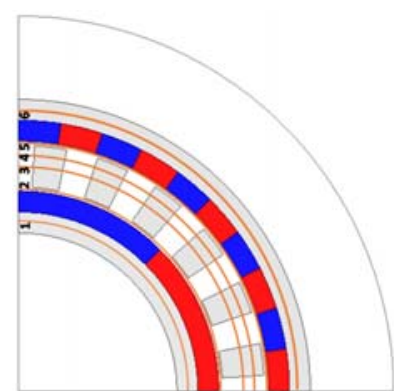

(d)
Fig. 8. Studied MG: (a) mesh elements; (b) magnetic flux lines, (c) magnetic flux density distribution, and (d) validation paths.

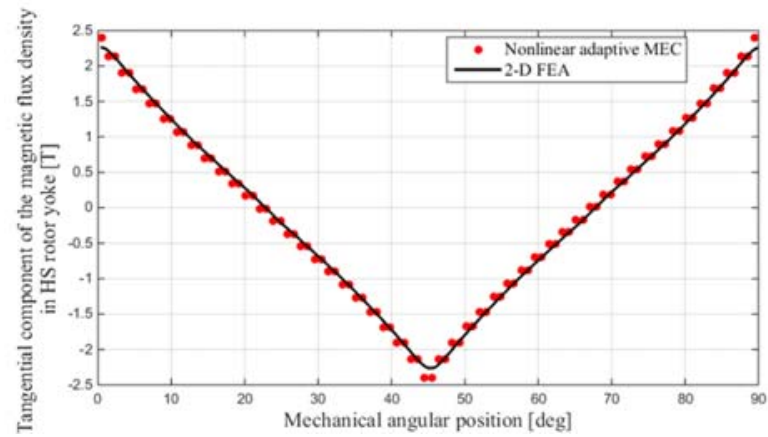

Fig. 9. Tangential component of the magnetic flux density in HS rotor yoke (i.e., path 1)

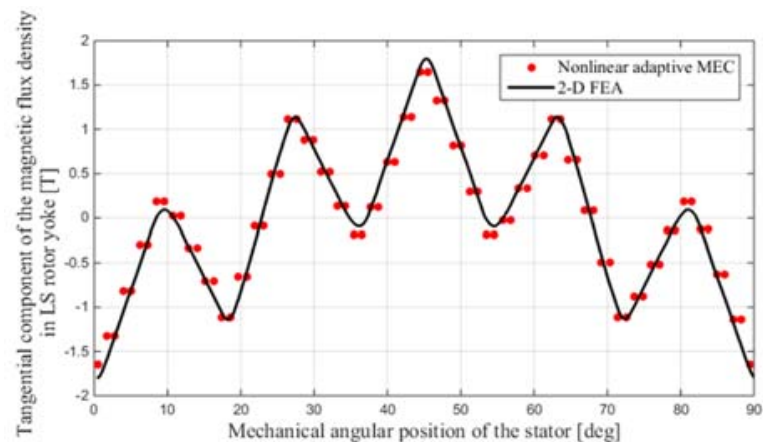

Fig. 10. Tangential component of the magnetic flux density in LS rotor yoke (i.e., path 6 )

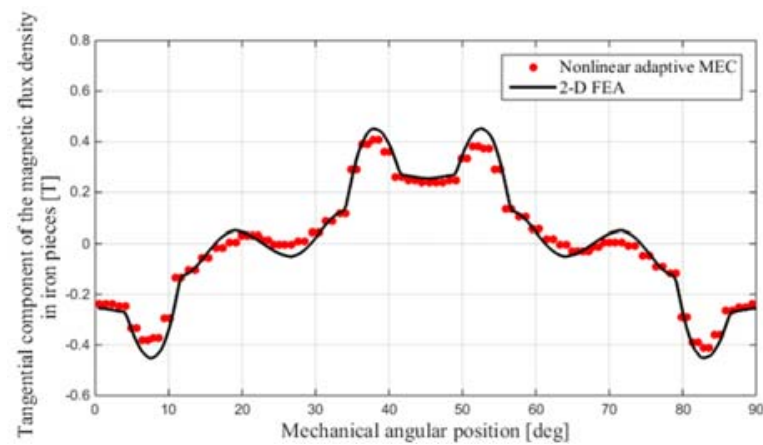

Fig. 11. Tangential component of the magnetic flux density in iron pieces (i.e., path 3 )

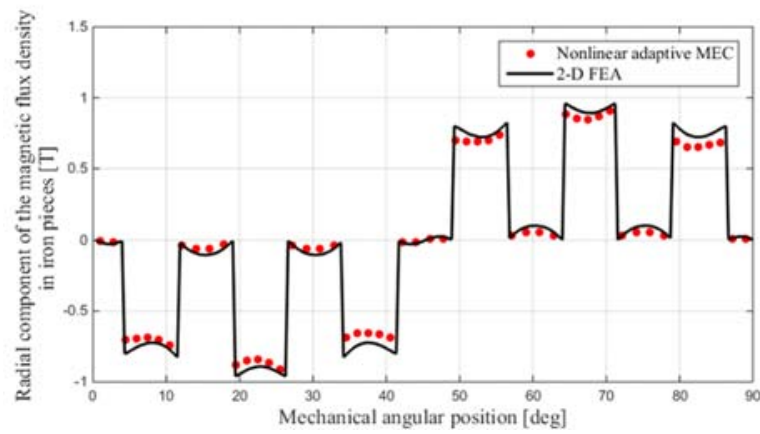

Fig. 12. Radial component of the magnetic flux density in iron pieces (i.e., path 4) 


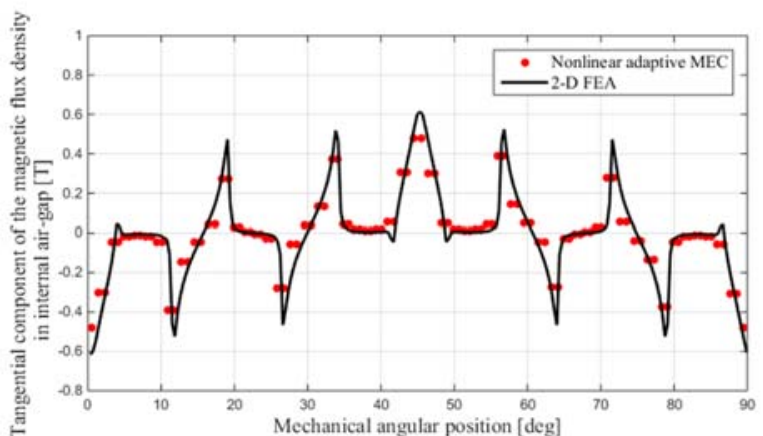

(a)

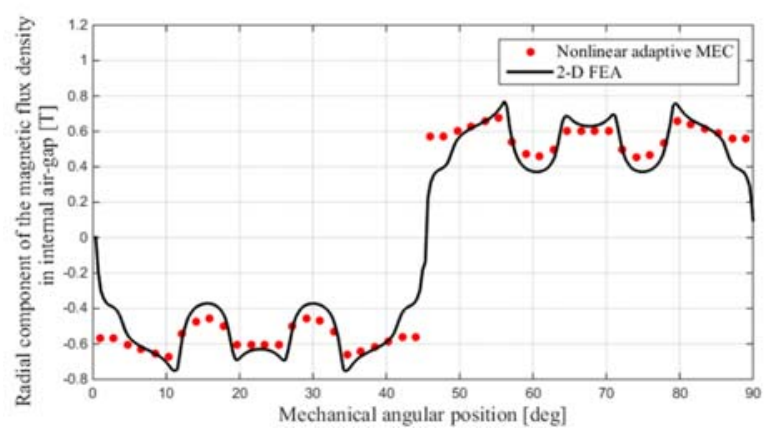

(b)

Fig. 13. Magnetic flux density in the internal air-gap (i.e., path 2): (a) tangential component, and (b) radial component.

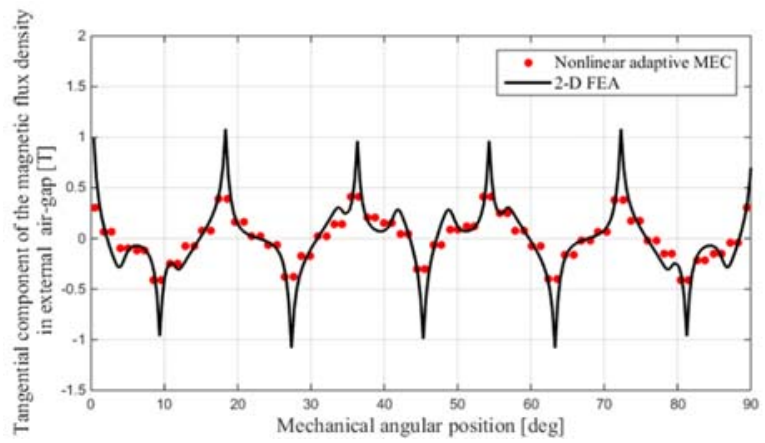

(a)

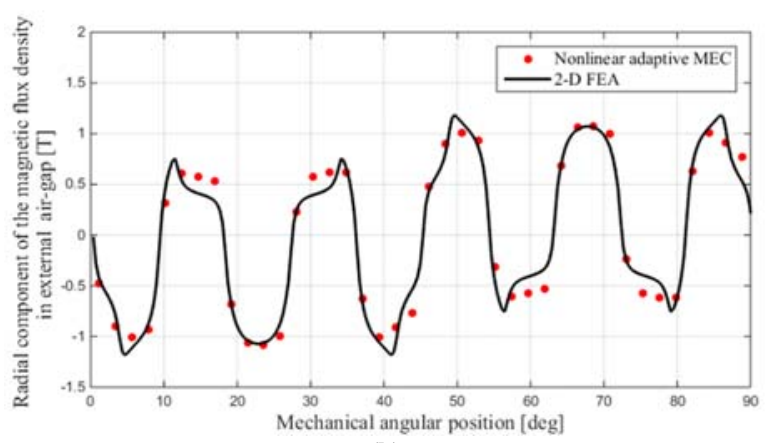

(b)

Fig. 14. Magnetic flux density in the external air-gap (i.e., path 5): (a) tangential component, and (b) radial component.

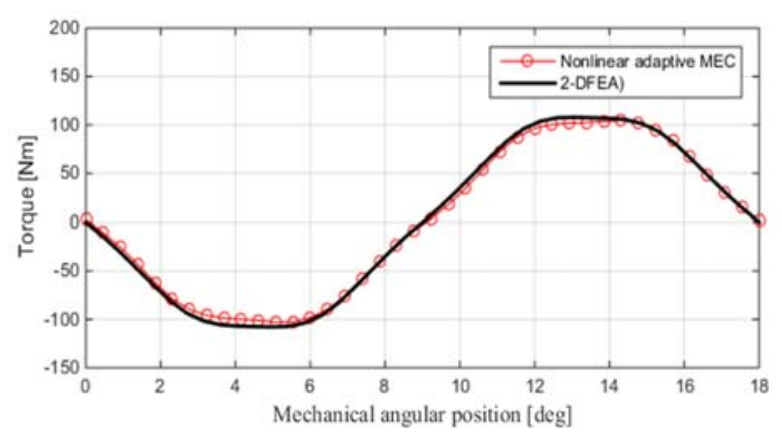

Fig. 15. Stall torque of the MG.

\section{Results Comparison and Discussion}

The magnetic flux density has been calculated in the different parts of the MG, and has been compared to 2-D FEA [see Fig. 9-Fig. 14]. The main validation paths $1-6$ are shown in Fig. 8 . The good correlation with the results obtained using 2-D FEA confirms the reliability of the proposed method. It is important to note that the magnetic flux density in highly saturated zones (i.e., in the LS and HS rotor yokes) has been calculated with high accuracy.

By applying the Maxwell stress tensor formula (4), the maximum torque that can be transmitted by the MG (i.e., the stall torque) has been determined by means of a locked rotor calculation, by maintaining the LS rotor fixed. As shown in Fig. 15, the maximum torque calculated with the proposed MEC is $102 \mathrm{Nm}$, which is in good agreement with the result obtained by $2-\mathrm{D}$ FEA $(105 \mathrm{Nm})$. The error is lower than $3 \%$.

\section{CONCLUSION}

In this paper, a nonlinear adaptive MEC has been developed for a magnetic gear equipped with surface-mounted PMs. The magnetic flux density can be calculated in the different zones of the magnetic gear with high accuracy. The radial and tangential components of the magnetic flux density have been compared to the results obtained with 2-D FEA for different paths. Moreover, the motion has been considered in the proposed model. Thus, the stall torque can be deducted with high accuracy (error lower than 3\%).

The proposed MEC neglects the end-effect, which can influence substantially the results, especially when the iron stack length is too short comparatively to the diameter. Thus, future work will focus on the improvement of the model to account for the end-effects with comparison to 3-D FEA. Furthermore, the improved MEC will be coupled to an optimization tool in order to maximize the torque per volume ratio while minimizing the $\mathrm{PM}$ weight.

\section{REFERENCES}

[1] K. Atallah, and D. Howe, "A Novel High-Performance Magnetic Gear", IEEE Trans. on Magn. , vol. 37, no. 4, pp. 2844-2846, July 2001.

[2] K. Atallah, S. D. Calverley, and D. Howe, "Design, Analysis and Realisation of a High-Performance Magnetic Gear", in IEE Proc. Electr. Pow. Appl ., vol. 151, no. 2, pp. 135-143, March 2004

[3] L. Jian, K. T. Chau, Y. Gong, J. Z. Jiang, C. Yu, and W. Li, "Comparison of Coaxial Magnetic Gears With Different Topologies", IEEE Trans. on Magn., vol. 45 , no. 10 , pp. 4526-4529, Oct. 2009.

[4] E. Gouda, S. Mezani, L. Baghli, and A. Rezzoug, "Comparison Study Between Mechanical and Magnetic Planetary Gears", IEEE Trans. on Magn. , vol. 47, no. 2, pp. 439-450, Feb. 2011 
[5] P. O. Rasmussen, T. O. Andersen, F. T. Jorgensen, and O. Nielsen "Development of a High-Performance Magnetic Gear", IEEE Trans. on Ind. Appl., vol. 41, no. 3, pp. 764-770, May./June 2005.

[6] N. W. Frank, and H. A. Toliyat, "Analysis of the Concentric Planetary Magnetic Gear With Strengthened Stator and Interior Permanent Magnet Inner Rotor", IEEE Trans. on Ind. Appl., vol. 47, no. 4, pp. 1652-1660, July/Aug. 2011.

[7] K. K. Uppalapati, J. Z. Bird, D. Jia, J. Garner, and A. Zhou, "Performance of a Magnetic Gear Using Ferrite Magnets for Low Speed Ocean Power Generation", in Proceed. of Ener. Conv. Cong. and Expo. (ECCE), Raleigh, USA, Sep. 15-20, 2012.

[8] K. T. Chau, D. Zhang, J. Z. Jiang, C. Liu, and Y. Zhang, "Design of a MagneticGeared Outer-Rotor Permanent-Magnet Brushless Motor for Electric Vehicles", IEEE Trans. on Magn., vol. 43, no. 6, pp. 2504-2506, June 2007.

[9] S. Mezani, K. Atallah, and D. Howe, "A High-Performance Axial-Field Magnetic Gear,” Journal of Appl. Phys., vol. 99, pp. 08R303-1-08R303-3, 2006.

[10] V. M. Acharya, J. Bird, and M. Calvin, "A Flux Focusing Axial Magnetic Gear", IEEE Trans. on Magn. , vol. 49, no. 7, pp. 4092-4095, July 2013.

[11] W. Bomela, J. Bird, and V. M. Acharya, "The Performance of a Transverse Flux Magnetic Gear", IEEE Trans. on Magn. , vol. 50, no. 1, pp. 4349-4352, Nov. 2008

[12] Y. Chen, and W. Fu, "A Novel Hybrid-Flux Magnetic Gear and Its Performance Analysis Using the 3-D Finite Element Method", in Energies, vol. 8, pp. 3313$3327,2015$.

[13] K. Atallah, J. Rens, S. Mezani, and D. Howe, "A Novel Pseud Direct-Drive Brushless Permanent Magnet Machine", IEEE Trans. on Magn. , vol. 44, no. 1 , pp. 5507-5521, Nov. 2008 .

[14] P. O. Rasmussen, H. H. Mortensen, T. N. Matzen, T. M. Jahns, and H. A. Toliyat, "Motor Integrated Permanent Magnet Gear With a Wide Torque-Speed Range", in Proceed. of Ener. Conv. Cong. and Expo. (ECCE), San Jose, USA, Sep. 2024, 2009.

[15] E. Morimoto; K. Hirata, N. Niguchi, and Y. Ohno, "Design and Analysiss of Magnetic-Geared Motor With Field Winding”, IEEE Trans. on Magn., vol. 50, no. 11, 8204204, Nov. 2014.

[16] R. J. Wang, L. Bronn, S. Gerber, and P. M. Tlali, "Design and Evaluation of a Disc-Type Magnetically Geared PM Wind Generator", in Proc. 4th Int. Conf Power Eng., Energy Elect. Drives (POWERENG), pp.1259 -1264, May 2013.

[17] L. Jian and K. T. Chau, "Analytical calculation of magnetic field distribution in coaxial magnetic gears," Progress in Electr. Resear. , vol. 92, pp. 1-16, 2009.

[18] T. Lubin, S. Mezani, and A. Rezzoug, "Analytical Computation of the Magnetic Field Distribution in a Magnetic Gears", IEEE Trans. on Magn. , vol. 46, no. 7 2611-2621, July 2010.

[19] Y.-J. Ge, C.-Y. Nie, and Q. Xin, "A Three Dimensional Analytical Calculation of the Air-Gap Magnetic Field and Torque of Coaxial Magnetic Gears," Progress in Electr. Resear., vol. 131, pp. 391-407, 2012.

[20] A. Penzkofer; and K. Atallah, "Analytical Modeling and Optimization of PseudoDirect Drive Permanent Magnet Machines for Large Wind Turbine", IEEE Trans. on Magn., vol. 51, no. 12, 8700814, Dec. 2015.

[21] M. Fukuoka, K. Nakamura, and O. Ichinokura, "Dynamic Analysis of PlanetaryType Magnetic Gear Based on Reluctance Network Analysis," IEEE Trans. on Magn, vol. 47, no. 10, pp. 2414-2417, 2011.

[22] M. Fukuoka, K. Nakamura, and O. Ichinokura, "A Method for Optimizing the Design of SPM Type Magnetic Gear Based on Reluctance Network Analysis', in Proceed. Int. Conf. on Elect. Mach. (ICEM), Marseille, France, Sept. 2-5, 2012.

[23] V. Ostovic, "A Simplified Approach to Magnetic Equivalent Circuit Modeling of Induction Machines", IEEE Trans. on Ind. Appl., vol. 24, no. 2, pp. 308-316, March/April 1988.

[24] J.K. Tangudu, T.M. Jahns, A. EL-Refaie, and Z.Q. Zhu, "Lumped Parameter Magnetic Circuit Model for Fractional-Slot Concentrated-Winding Interior Permanent Magnet Machines", in Proc. ECCE, San José, California, Sept. 20 24, 2009.

[25] B. Nedjar, S. Hlioui, L. Vido, Y. Amara, and M. Gabsi, "Flux focusing permanent magnet synchronous machine modeling by 2D Magnetic Equivalent Circuit", in Proc. EPE-PEMC, Novi Sad, Serbia, Sept. 04-06, 2012.

[26] D.J. Gomez, A.L. Rodriguez, I. Villar, A. Lopez-de Heredia, I. EtxeberriaOtadui, and Z.Q. Zhu, "Improved Permeance Network Model for Embedded Magnet Synchronous Machines", in Proc. ICEM, Berlin, Germany, Sept. 03-05, 2014.

[27] F. Dubas, R. Benlamine, S-A. Randi, D. Lhotellier, and C. Espanet, "2-D or Quasi 3-D Nonlinear Adaptive Magnetic Equivalent Circuit, Part I: Generalized Modeling with Air-Gap Sliding-Line Technic", Applied Mathematical Modelling, under review.
[28] R. Benlamine, F. Dubas, S-A. Randi, D. Lhotellier, and C. Espanet, "2-D or Quasi 3-D Nonlinear Adaptive Magnetic Equivalent Circuit, Part II: Application to Axial-Flux Interior Permanent-Magnet Synchronous Machines", Applied Mathematical Modelling, under review.

[29] R. Benlamine, F. Dubas, S-A. Randi, D. Lhotellier, and C. Espanet, "Modeling of an Axial-Flux Interior PMs Machine for an Automotive Application Using Magnetic Equivalent Circuit", in Proc. ICEMS, Pattaya, Thailand, Oct. 25-28, 2015

[30] R. Benlamine, F. Dubas, and C. Espanet, "Nonlinear Adaptive Magnetic Equivalent Circuit of a Radial-Flux Interior Permanent-Magnet Machine Using Air-Gap Sliding-Line Technic", Applied Mathematical Modelling, under review.

[31] A. Marrocco, "Analyse numérique de problèmes d'électrotechnique", Ann. Sc. Math., vol. 01, pp. 271-296, 1977.

\section{BIOGRAPHIES}

Raouf Benlamine was born in Algiers, Algeria, in 1987. He received the Engineering degree in electrical engineering from Ecole Nationale Polytechnique, Algiers, in 2010, and the Master degree in electrification and automotive propulsion from the Ecole Centrale de Paris, France, in 2011. In 2014, he received his Ph.D. degree from the University of Franche-Comte (France) in collaboration with Renault. His doctoral research dealt with the design and the optimization of axial-flux PM machines.

Since 2015, Dr Benlamine is electrical machines design engineer at VEDECOM Institute. His current research interests include the modeling and the design of electromagnetic devices, in particular, synchronous PM machines (axial and radial-flux).

Tahar Hamiti was born in Larbàa Nath Irathen, Algeria, in 1979. He received the Ingénieur d'Etat degree in automatic control systems from the University of Tizi-Ouzou, Tizi-Ouzou, Algeria, and the Ph.D. degree in electrical engineering from the University of Nancy I, Nancy, France.

From 2010 to 2015 , he was a Research Fellow and subsequently a Lecturer within the Power Electronics, Machines and Control Group, The University of Nottingham, UK

In 2015 Dr Hamiti joined VEDECOM, a French institute for energy transition to work on novel electrical machines for electric and hybrid vehicles. His research interests include modeling, optimal design, and control of highperformance electrical machines for transportation applications and power generation.

Franck Vangraefschèpe received an engineering degree in Aeronautics from Supaéro, Toulouse, France, in 1998 and a Master degree in Automotive from ENSPM, Rueil-Malmaison, France, in 2000.

He first worked on combustion engines at IFPEN, Rueil-Malmaison, France, where he optimized efficiency and pollutant emissions of gasoline combustion. He then changed to work on Hybrid and Electric Vehicles globally, and on electric powertrains more specifically. $\mathrm{He}$ is currently electric motors development project manager at VEDECOM, Versailles, France.

Frédéric Dubas was born in Vesoul, France, in 1978. He received the Degree from the University of Franche-Comte (UFC), Belfort, France, in 2002, and the Ph.D. degree from the UFC, in 2006, with a focus on the design and the optimization of high-speed surface-mounted permanent-magnet (PM) motor for the drive of a fuel cell air-compressor.

$\mathrm{He}$ is currently an Associate Professor with the ENERGY Department, FEMTO-ST Institute, UFC where he is the Head of the "Unconventional Thermal and Electrical Machines" Team. He is with ALSTOM Transports, Ornans, France, and RENAULT Technocenter, Guyancourt, France, where he is involved in the modeling, design and optimization of electrical systems and, in particular, induction and PM synchronous (radial and/or axial flux) machines, creative problem solving, and electrical propulsion/traction. He has authored over 50 refereed publications and a patent about the manufacturing of axial-flux PM machines with flux-focusing.

Dr. Dubas received the Prize Paper Awards in the IEEE Conference Vehicle Power and Propulsion (VPPC) in 2005

Dominique Lhotellier spent nearly 20 years on innovative solutions in power electronics and e-motors for affordable more electric cars, at RENAULT. He is now in charge of Electrification projects at VEDECOM, a new French institute for more electric cars. 